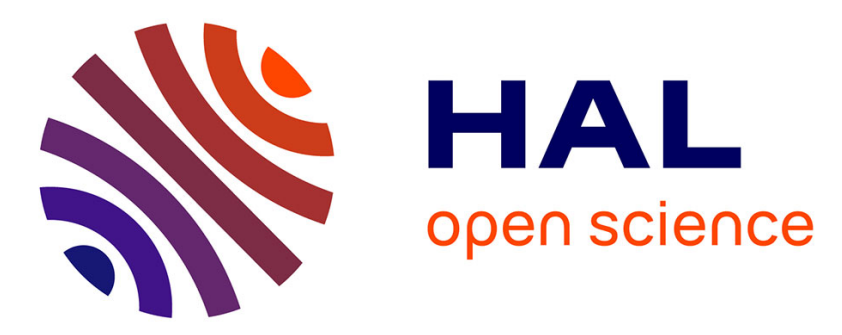

\title{
Effects of achievement goals on self-regulation of eating attitudes among elite female athletes: An experimental study
}

Stéphanie Scoffier-Mériaux, Christophe Gernigon, Fabienne d'Arripe-Longueville

\section{To cite this version:}

Stéphanie Scoffier-Mériaux, Christophe Gernigon, Fabienne d'Arripe-Longueville. Effects of achievement goals on self-regulation of eating attitudes among elite female athletes: An experimental study. Psychology of Sport and Exercise, 2012, 10.1016/j.psychsport.2011.11.005 . hal-02524797

\section{HAL Id: hal-02524797 \\ https://hal.univ-cotedazur.fr/hal-02524797}

Submitted on 3 Apr 2020

HAL is a multi-disciplinary open access archive for the deposit and dissemination of scientific research documents, whether they are published or not. The documents may come from teaching and research institutions in France or abroad, or from public or private research centers.
L'archive ouverte pluridisciplinaire HAL, est destinée au dépôt et à la diffusion de documents scientifiques de niveau recherche, publiés ou non, émanant des établissements d'enseignement et de recherche français ou étrangers, des laboratoires publics ou privés. 
Elsevier Editorial System(tm) for Psychology of Sport \& Exercise Manuscript Draft

Manuscript Number: PSE-D-10-00119R2

Title: Effects of Achievement Goals on Self-Regulation of Eating Attitudes in Elite Female Athletes: An Experimental Study

Article Type: Research Paper

Section/Category: Exercise \& Health

Keywords: achievement motivation, disordered eating attitudes, high-level sport, figure skating

Corresponding Author: Dr. Scoffier Stéphanie,

Corresponding Author's Institution: UNIVERSITE DE NICE SOPHIA ANTIPOLIS

First Author: Scoffier Stéphanie

Order of Authors: Scoffier Stéphanie; Christophe Gernigon; Fabienne d'Arripe-Longueville

Abstract: Introduction: The influence of achievement goals on eating attitudes has mainly been examined through correlational studies (e.g., De Bruin et al., 2009; Duda \& Kim, 1997), and none of the studies to date has focused on the self-regulation of eating attitudes in athletes. The present study experimentally tested the effects of achievement goals on both self-reported (Study 1) and behavioral indices (Study 2) of the self-regulation of eating attitudes in female figure skaters.

Method: Elite female figure skaters (Study 1: $n=44$; Study 2: $n=54$ ) were randomly assigned to one of four conditions designed to induce specific goal involvement (performance-approach, masteryapproach, performance-avoidance, and mastery-avoidance) or a control condition (no goal induction). The participants in Study 1 completed the Self-Regulation of Eating Attitudes in Sport Scale (SREASS, Scoffier et al., 2010c) and those in Study 2 completed a virtual behavioral measure of self-regulation of eating attitudes (VSSR; Scoffier, 2009).

Results: Variance analyses indicated that induced mastery-approach goals and performance-avoidance goals resulted in higher scores for self-regulation of eating attitudes than induced performanceapproach goals and mastery-avoidance goals. The relationships were the same at both self-reported and behavioral levels.

Discussion: This experimental study confirms the findings of previous correlational works and shows that achievement goals contribute to the causal processes of self-regulation of eating attitudes. These findings might help to prevent eating disorders in female athletes by providing guidance for the development of adapted motivational strategies.

Suggested Reviewers: CHRISTY GREENLEAF

JUSTINE REELS

KARIN DE BRUIN 
Stéphanie Scoffier

Faculté des Sciences du Sport - Université de Nice-Sophia-Antipolis

261, Route de Grenoble - BP 3259

06205 Nice cedex 3

Tel: 33492296529

Fax: 33492296537

Email: scoffier@unice.fr

Nice, 17 April 2011

To: Dr D. ALFERMANN, Dr M. HAGGER,

Dear Dr D. ALFERMANN, Dr M. HAGGER,

Please consider the following revision of the article, " Effects of Achievement Goals on Self-Regulation of Eating Attitudes among Elite Female Athletes: An Experimental Study ", for publication in PSYCHOLOGY OF SPORT AND EXERCISE. It is 27 pages long and includes two tables.

This submitted paper is original and unpublished, and is not under consideration for publication elsewhere.

Sincerely,

Stéphanie Scoffier 
Running head: ACHIEVEMENT GOALS AND SELF-REGULATION OF EATING ATTITUDES

Effects of Achievement Goals on Self-Regulation of Eating Attitudes among Elite Female Athletes: An Experimental Study

Stéphanie Scoffier ${ }^{1}$, Christophe Gernigon ${ }^{2}$, \& Fabienne d'Arripe-Longueville ${ }^{1}$

${ }^{1}$ University of Nice Sophia-Antipolis, LAMHES, France

${ }^{2}$ Montpellier I University, France

Address correspondence to:

Stéphanie Scoffier

UFR STAPS - Université de Nice Sophia-Antipolis

261 Route de Grenoble, BP 3259, 06205 Nice cedex 03 - France

Phone: ++ 334922965 29, Fax: ++ 334922965 37, E-mail: scoffier@unice.fr

Submitted date: May $30^{\text {th }} 2010$

Revised date: April $17^{\text {th }} 2011$ 


\begin{abstract}
Introduction: The influence of achievement goals on eating attitudes has mainly been examined through correlational studies (e.g., De Bruin et al., 2009; Duda \& Kim, 1997), and none of the studies to date has focused on the self-regulation of eating attitudes in athletes. The present study experimentally tested the effects of achievement goals on both self-reported (Study 1) and behavioral indices (Study 2) of the self-regulation of eating attitudes in female figure skaters.

Method: Elite female figure skaters (Study 1: $n=44$; Study 2: $n=54$ ) were randomly assigned to one of four conditions designed to induce specific goal involvement (performance-approach, mastery-approach, performance-avoidance, and mastery-avoidance) or a control condition (no goal induction). The participants in Study 1 completed the Self-Regulation of Eating Attitudes in Sport

11 Scale (SREASS, Scoffier et al., 2010c) and those in Study 2 completed a virtual behavioral measure of 12 self-regulation of eating attitudes (VSSR; Scoffier, 2009).

13 Results: Variance analyses indicated that induced mastery-approach goals and performance14 avoidance goals resulted in higher scores for self-regulation of eating attitudes than induced 15 performance-approach goals and mastery-avoidance goals. The relationships were the same at both 16 self-reported and behavioral levels.

17 Discussion: This experimental study confirms the findings of previous correlational works and 18 shows that achievement goals contribute to the causal processes of self-regulation of eating attitudes. 19 These findings might help to prevent eating disorders in female athletes by providing guidance for the 20 development of adapted motivational strategies.
\end{abstract}

21 Keywords: achievement motivation, disordered eating attitudes, high-level sport, figure skating. 


\section{Effects of Achievement Goals on Self-Regulation of Eating Attitudes in Elite Female Athletes: An} Experimental Study

The term "disordered eating attitudes" describes unhealthy attitudes and behaviors that range from strict dietary habits in order to lose or maintain weight to severe food restriction (Hobart \& Smucker, 2000). In the psychosocial literature, they are generally considered to be sub-clinical (Petrie \& Greenleaf, 2007), and diagnosis is based on self-reported instruments. Adolescent girls are especially at risk of developing disordered eating attitudes (Jacobi, Hayward, de Zwaan, Kraemer, \& Agras, 2004; Polivy, Herman, Mills, \& Wheeler, 2003), as are young athletes in aesthetic sports like gymnastics and figure skating (Beals \& Manore, 2000; Scoffier, Maïano, \& Arripe-Longueville (d'), 2010a; Smolak, Murnen, \& Ruble, 2000; Sherman \& Thompson, 2009; Sundgot-Borgen \& Torstveit, 2004). In these sports, internalization of the thin ideal and coach pressure about weight are important risk factors for disturbed body image and eating pathology.

Sports that require the public display of physical grace and skill are typical achievement contexts that favor eating disorders (Scoffier et al., 2010a), and achievement goal theories might therefore provide insight into the disordered eating of female aesthetic athletes. An achievement goal is a cognitive construction that reflects the aim that a person pursues in order to obtain success or avoid failure (Elliot, 2005). It is a cognitive representation of a final state that gives direction to action (Pintrich, 2000). Several authors have examined the relationships between both individual and contextual (i.e., the motivational climate) goal orientations and eating disorders within a bidimensional framework of achievement goals (De Bruin, Bakker, \& Oudejans, 2009; Duda, 2001). However, this research has been correlational in nature, which limits the causal interpretations about the effect of achievement goals on eating attitudes. Hence, there is a need to test these potential effects through experimental designs.

Behavioral measures of eating attitudes may raise ethical issues. As an extreme example, the observation and documentation of compulsive overeating and compensatory weight control behaviors outside of a treatment context would be profoundly disrespectful of the individual's integrity. Most investigators of disordered eating attitudes have thus generally relied on self-reported measures like the Eating Attitude Test (Garner, Olmsted, Bohr, \& Garfinkel 1982) or the Dutch Questionnaire for Eating Behaviours (van Strien, Frijters, Bergers, \& Defares, 1986). Yet, several authors have shown that self-regulation and self-regulatory efficacy have an influence on eating attitudes in daily life (Abusabha \& Achterberg, 1997; Baranowski et al., 1997; Glynn \& Ruderman, 1986; Pinto, Guarda, Heinberg, \& DiClemente, 2006) and, more recently, in sports contexts (Scoffier, Corrion, Paquet, \& Arripe-Longueville (d'), 2010c). The self-regulation of eating attitudes refers to the feeling of confidence an individual has about being able to eat without engaging in disordered eating behavior or experiencing undue emotional distress (Pinto, Heinberg, Coughlin, Fava, \& Guarda, 2008). Selfregulation mechanisms are especially crucial for athletes during competitive periods, when both social comparison and social pressure to conform to an ideal body weight are high (Sherman \& Thompson, 
2009). However, the influence of achievement goals on the self-regulation of eating attitudes in athletes has not been examined. The purpose of the present study was therefore to experimentally test the effects of achievement goals on both self-reported and behavioral indices of self-regulation of eating attitudes in female figure skaters.

\section{Self-Regulation and Eating Attitudes}

The concept of self-regulation has been explored in many fields of study. Self-regulation refers to the capacity to control one's behavior or perform an activity, and it is a powerful predictor of health-related behaviors (e.g., Rasmussen, Wrosch, Scheier, \& Carver, 2006). The self-regulation of eating attitudes is related to the individual's concerns about his or her body, the intensity of exercise and physical activities (Desharnais, Bouillon, \& Godin, 1986; McAuley, 1992; McAuley \& Mihalko, 1998), and the degree of engagement in weight loss and nutrition programs (see Herman \& Polivy, 2004, for a review). Altfas (2002) and Holtkamp, Konrad, and Müller (2004) showed that disordered eating attitudes were more frequent in individuals with a low capacity for self-regulated eating and this was corroborated by many of the studies cited in AbuSabha and Achterberg's (1997) review of the literature. For example, the capacity for self-regulated eating has been found to affect students' control of fruit and vegetable consumption (Baranowski, Perry, \& Parcel, 1997). Recently, the self-regulation of eating attitudes was found to be related to disordered eating in the sports context (Scoffier, Corrion, Paquet, \& Arripe-Longueville (d'), 2010c; Scoffier, Paquet, \& Arripe-Longueville (d'), 2010b).

Self-regulation of eating attitudes is classically assessed with Glynn and Ruderman's (1986) Eating Self-Efficacy Scale (ESES), which is composed of 25 items loaded on two factors: negative affects and socially acceptable circumstances, and the Eating Disorder Recovery Self-Efficacy Questionnaire (EDRSQ) of Pinto et al. (Pinto et al., 2006; Pinto et al., 2008), which is composed of 23 items loaded on two factors: normative self-regulation of eating attitudes and the feeling of selfefficacy concerning self-image. However, as these tools are not adapted to the sports context, Scoffier et al. (2010c) recently developed the Self-Regulation of Eating Attitudes in Sport Scale (SREASS). The SREASS is composed of 16 items loaded on five factors pertaining to the self-regulation of eating attitudes in the following contexts: (a) food temptation (e.g., Do you feel capable of controlling what you eat when tempting food is put before you?), (b) negative affects (e.g., Do you feel capable of controlling what you eat when you are anxious or worried?), (c) social interaction (e.g., Do you feel capable of eating with your training partners without depriving yourself?), (d) lack of compensatory strategies (e.g., Do you feel capable of making yourself vomit if you've just eaten cake at a birthday celebration?), and (e) lack of anticipation of consequences on performance (e.g., Do you feel capable of eating a dessert without thinking about the consequences this may have on your next competition?). The questionnaire includes two inverted items.

In addition to the self-reported measures of self-regulation of eating attitudes, these attitudes need to be assessed at the behavioral level, which directly affects personal health. However, the objective measurement of disordered eating behavior is difficult to defend from an ethical standpoint. 
1 For example, the daily assessment of energy intake may create social pressure on study participants and cause desirability bias. Therefore, indirect measures are needed. Scoffier (2009) developed the Virtual Self Service Restaurant (VSSR), an online interface that allows individuals to select foods for every meal of the day and then calculates the energy intake and expenditure based on these food choices.

\section{Achievement Goals and Eating Attitudes in Athletes}

Although several factors contributing to disordered eating attitudes have been studied in social psychology (Jacobi et al., 2004) and sports psychology (Petrie \& Greenleaf, 2007), the role of achievement goals has not received much attention. The most recent theory of achievement goals presents a four-goal framework (Elliot \& McGregor, 2001), with the four types of goals lying along two dimensions. The first dimension concerns the self-referenced (i.e., progressing in or mastering a task) or norm-referenced (i.e., outperforming others) nature of the competence needed in pursuit of a goal. Mastery and performance goals thus involve a sense of competence that is self- and normreferenced, respectively. This distinction reflects the former two-goal framework (e.g., Dweck, 1986) in which mastery and performance goals were sometimes respectively called task and ego orientations (Nicholls, 1989). The second dimension refers to the appetitive and aversive valences of an outcome, which respectively elicit approach and avoidance goals. The four achievement goals in Elliot and McGregor's framework are thus: (a) mastery-approach (MAp) goals, which combine a self-referenced sense of competence and an appetitive outcome valence; (b) mastery-avoidance (MAv) goals, which combine a self-referenced sense of competence and an aversive outcome valence; (c) performanceapproach (PAp) goals, which combine a norm-referenced sense of competence and an appetitive valence of the outcome; and (d) performance-avoidance (PAv) goals, which combine a normative sense of competence and an aversive valence of the outcome.

Duda and colleagues showed that an environment that encourages task orientation protects female gymnasts from disordered eating attitudes, whereas the perception of a performance-oriented climate has a negative impact on body image and weight concerns and predisposes these athletes to disordered eating and low self-esteem (Duda, 2001; Duda \& Bernadot, 1997; Duda \& Kim, 1997). Moreover, Chi (2004) showed that performance goals could lead to destructive behaviors like drug abuse, alcoholism, or extreme weight control. De Bruin et al. (2009) observed that an ego orientation combined with perceptions of an ego-involving training climate is positively related to dieting in female gymnasts and dancers. They also found that the perception of a task-involving climate was negatively related to dieting. Taken as a whole, these results confirm that achievement goal theory is a heuristic framework that can account for eating disorders.

Scoffier, Corrion, and d'Arripe-Longueville (2009) examined eating attitudes in elite female athletes using the framework of Elliot and McGregor (2001). They showed that performance approach (Pap) and mastery avoidance (MAv) goals positively predicted disordered eating attitudes and could thus be assumed to be risk factors. In contrast to the findings of De Bruin et al. (2009), mastery 
approach (Map) goals did not predict disordered eating attitudes and performance avoidance (PAv) goals, which are generally associated with low perceived competence (Elliot \& Church, 1997), appeared as protective factors. Therefore, avoidance strategies might have protected these athletes from the development of disordered eating attitudes.

The studies that have examined the influence of achievement motivation on eating attitudes in athletes have been correlational in nature and thus few conclusions could be drawn about the causal role of achievement goals (De Bruin et al., 2009; Duda, 2001; Duda \& Bernadot, 1997; Duda \& Kim, 1997; Scoffier et al., 2009). Experimental investigations are needed to overcome this limitation.

Furthermore, no study has yet tested the impact of the activation of specific achievement goals on the self-regulation of eating attitudes.

The aim of this study was twofold. We first experimentally tested the influence of achievement goals on the self-reported measure of self-regulation of eating attitudes in elite female figure skaters, using the SREASS (Scoffier et al., 2009). We then tested the influence of achievement goals on the behavioral measure of self-regulation of eating attitudes in the same type of athlete, using Scoffier's (2009) Virtual Self-Service Restaurant (VSSR). This online tool permits a virtual projection of eating attitudes at a specific moment in time in a particular motivational context. In both cases, we expected to confirm experimentally the results of earlier correlational studies. It was assumed that capacities for self-regulation of eating attitudes measured with both self-reported and behavioral instruments would be higher in conditions of PAv and MAp goals than in conditions of PAp and MAv goals (De Bruin et al., 2009; Duda, 2001; Scoffier et al., 2009).

\section{Preliminary Study}

A preliminary study tested whether the four states of goal involvement could be activated by the experimental conditions.

\section{Method}

Participants. Forty-four volunteer student athletes $\left(M_{a g e}=21\right.$ years; $\left.S D_{a g e}=.28\right)$ were recruited to test the impact of the instructions intended to induce specific achievement goals in the first experimental protocol. They were randomly assigned to one of four groups and given instructions designed to induce one of the four types of goals in the $2 \times 2$ model.

Induction of the experimental conditions. One of the five sets of instructions below was given to the members of each group in order to induce the corresponding goal orientation: $\operatorname{MAp}(n=11)$, $\operatorname{PAp}(n=11), \operatorname{MAv}(n=11)$, and PAv $(n=11)$.

Instructions for the "Mastery-Approach Goals" group: "Imagine that it's early summer. You're in training and you need to make as much technical progress as possible and master as many technical elements as you can."

Instructions for the "Performance-Approach Goals" group: "Imagine that you're in training just before the French Championship selections. Your coach will be filming everyone as they do their free 
1 program. Then everyone will review the best programs and the coach will select the best skaters. Your performance has to be better than everyone else's if you want to be selected."

Instructions for the "Mastery-Avoidance Goals" group: "Imagine that it's early summer. You're in training and you need to avoid making as many technical mistakes as you can and skating worse than usual."

Instructions for the "Performance-Avoidance Goals" group: "Imagine that you're in training just before the French Championship selections. Your coach will be filming everyone as they do their free program. Then everyone will review the best programs and the coach will eliminate the skaters whose performances were least good. You don't want to perform worse than the others so you can avoid being among the skaters eliminated."

Instructions for the control group: "You're in training and, as you do every day, you manage to balance your day between school and skating."

After reading the instructions, the 44 volunteer student athletes responded to the approach and avoidance questionnaire for sports and physical education settings (Schiano-Lomoriello, Da Fonséca, \& Cury, 2005). The questionnaire had been further adapted for only a sports setting and not physical education, as reflected in the following examples: "this year" was changed to "this season" and "pupils" was changed to "practitioners in my sport." Three items assessed each goal (MAp: e.g., "This season, I want to learn as much as possible in my sport"; PAp: e.g., "This season, it's important for me to do better than other athletes"; MAv: e.g., "My goal this season is to avoid learning less than I possibly could in my sport"; and PAv: e.g., "My goal this season is to avoid performing worse than other athletes"). Participants responded on a Likert-type scale from 1 (strongly disagree) to 7 (strongly agree). Each subscale exhibited satisfactory internal consistency (i.e., $\alpha>.75$ ).

\section{Results}

A one-way analysis of variance (Instructions $\times 4$ ) was used to test the effects of the instructions on the scores for achievement goals. The instructions had significant effects on every goal: MAp, $F$ ( 3 , $40)=67.63, p<.01)$, PAp, $F(3,40)=47.25, p<.01), \mathrm{MAv}, F(3,40)=65.99, p<.01$, and PAv, $F$ $(3,40)=138.72, p<.01$. The post-hoc Student-Newman-Keuls tests then showed (a) significantly higher mean scores for MAp goals $(p<.05)$ when we induced MAp than in other conditions $\left(M_{\mathrm{MA}}=\right.$ $\left.6.73 ; M_{\mathrm{PA}}=2.18 ; M_{\mathrm{ME}}=2.21 ; M_{\mathrm{PE}}=2.64\right) ;(\mathrm{b})$ significantly higher mean scores for PAp goals ( $p<$ $.05)$ when we induced PAp than in other conditions $\left(M_{M A}=2.03 ; M_{P A}=6.55 ; M_{M E}=1.94 ; M_{P E}=\right.$ 2.88); (c) significantly higher mean scores for MAv goals $(p<.05)$ when we induced MAv than in other conditions $\left(M_{M A}=3.30 ; M_{P A}=2.00 ; M_{M E}=6.48 ; M_{P E}=1.97\right)$; and (d) significantly higher mean scores for PAv goals $(p<.05)$ when we induced PAv than in other conditions $\left(M_{M A}=1.61 ; M_{P A}=\right.$ $\left.2.52 ; M_{M E}=1.79 ; M_{P E}=6.64\right)$.

\section{Discussion}


This preliminary study confirmed that the instructions given to each group had the desired

impact, clearly demonstrating that each set of instructions resulted in the expression of a specific goal orientation.

\section{Study 1}

\section{Method}

Participants. Forty-four nationally ranked competitive figure skaters were recruited. The average age was 15.52 years (SDage $=2.43$ ) and all had been skating in competition for at least six years. These athletes were recruited because of their particular vulnerability to the development of disordered eating attitudes (Sundgot-Borgen, 1994) and their competitive experience. Their vulnerability was due to the strong emphasis on physical appearance in aesthetic sports: figure skaters are expected to conform to a sport-specific, ideal body shape. Judges promote an ideal of thinness and many skaters believe they need to reach this ideal to be attractive and successful (Sherman \& Thompson, 2009). The athletes were all volunteers and the parents of minors gave their consent.

Procedure. The figure skaters were invited to complete the SREASS online. This gave us the initial level of their self-regulation of eating attitudes in sports. They were then informed two days later by instant messaging that they had to read a set of instructions. The skaters were randomly assigned to one of five groups: four groups to induce the four types of goals: MAp $(n=8), \operatorname{PAp}(n=$ $10), \operatorname{MAv}(n=10), \operatorname{PAv}(n=8)$, and a fifth group that served as a control group $(n=8)$. They were then asked to complete a short version of the approach and avoidance questionnaire for sports and physical education settings to verify that each set of instructions actually induced the desired goal orientation in each group. In order to control for the first SREASS score, the participants completed this measure twice.

Measures. The self-reported measure of self-regulation of eating attitudes in sports was assessed with the SREASS developed and validated in French by Scoffier et al. (2010c). This tool is composed of five factors pertaining to the self-regulation of eating attitudes in the following contexts: (a) food temptation, (b) negative affects (c) social interaction, (d) lack of compensatory strategies, and (e) lack of anticipation of consequences on performance. This scale has shown high stability over a four-week period (test-retest reliability > .70; Scoffier et al., 2010c). The items were measured on a Likert-type scale from not at all capable (1) to completely capable (6). A global index of selfregulation of eating attitudes was calculated by averaging the responses to items from the five subscales. This index was shown to be positively related to such widely used measures as the Eating Attitudes Test (Scoffier et al., 2010c), thus confirming its external validity. In the present study, the scale provided good internal consistency coefficients for each time of measure $(\alpha>.80)$.

A short version of the approach and avoidance questionnaire for sports and physical education settings (Schiano-Lomoriello et al., 2005) was administered to check that each set of instructions actually induced the desired goal orientation in each group of figure skaters. 
Analyses. Kruskal-Wallis analysis of variance was used to verify that each set of instructions actually induced the desired goal orientation in each group. Then, after checking the assumptions required for this type of analysis (e.g., especially no inter-condition differences during the first measurement), one-way covariance analysis (Instructions $\times 5$ ) with the first score of self-regulation of eating attitudes as the covariable was used to test the experimental condition. Finally, post-hoc Bonferroni tests were performed to locate significant differences.

\section{Results}

Induction of experimental conditions. Kruskal-Wallis analysis of variance revealed a significant effect of the experimental conditions $(p \leq .05)$ : the participants in each goal-orientation group ranked this goal in first position (i.e., "the goal most important to me"), thus supporting the validity of the procedure. The participants in the control group ranked MAp goals in first position.

Self-regulation of eating attitudes. Table 1 presents the descriptive statistics for each experimental condition. Covariance analysis performed on the post-instruction scores of selfregulation of eating attitudes highlighted a significant effect of the covariable, the level of selfregulation of eating attitudes measured before the instructions $[(F(5,44)=14.94, p<.01)]$, and also an effect of the experimental conditions $[(F(5,44)=184.62, p<.001)]$. Subsequent post-hoc Bonferroni tests indicated that the scores of self-regulation of eating attitudes in sports were significantly lower for the MAv group $(p<.05)$ and the PAp group $(p<.05)$ compared with the control group. Moreover, these scores were significantly lower for the MAv group than for the MAp group $(p<.01)$ and for the PAp group than for the MAp group $(p<.01)$. However, the scores were higher for the PAv group than for the MAv group $(p<.01)$ and for the PAv group than for the PAp group $(p<.05)$.

\section{Discussion}

This study examined the influence of achievement goals on the self-reported measure of selfregulation of eating attitudes. Our findings extend the correlational studies of De Bruin et al. (2009) and Scoffier et al. (2009a) and confirm that MAv goals are negatively associated with the measure of self-regulation of eating attitudes, leading to disordered attitudes (Scoffier et al., 2009). Analysis in fact revealed that MAv goals resulted in less self-regulation of eating attitudes than PAv goals. In agreement with our hypothesis based on the work of Scoffier et al. (2009), PAv goals appeared as potential protective factors against disordered eating attitudes in that they were vectors for a higher level of self-regulation than MAv and PAp goals.

MAp goals seemed to offer better protection against disordered eating attitudes than MAv goals because they led to greater self-regulation of eating attitudes. Thus, as noted in the literature (De Bruin et al., 2009; Duda, 2001), MAp contributed to the adoption of adaptive achievement patterns, which was reflected by eating attitudes. Interestingly, the members of the control group displayed a tendency to spontaneously choose MAp and their level of self-regulation was quite similar to that of the MAp group. We conclude that this study demonstrated a tendency toward better self-regulation of 
1 eating attitudes in PAv and MAp conditions than in MAv conditions (De Bruin et al., 2009; Duda, 2001; Scoffier et al., 2009). In the next study, we further explored achievement goals by examining their impact on the behavioral measure of self-regulation of eating attitudes.

\section{Study 2}

\section{Method}

Participants. Another independent sample of 54 nationally ranked competitive figure skaters was recruited for this study. Their characteristics and the criteria to recruit them were the same as for Study 1 . The average age was 15.71 years $\left(S D_{a g e}=2.58\right)$ and all participants had been figure skating in competition for at least six years. They were volunteers and the parents of all minors gave their consent.

Procedure. The skaters were invited to complete the SREASS online and two days later they were invited into a room on their training site. As in Study 1, four groups of figure skaters were composed based on the goals that were induced with specific instructions: MAp $(n=10)$, PAp $(n=$ 12), MAv $(n=12)$, and PAv $(n=10)$. A fifth group served as a control group $(n=10)$. The short version of the approach and avoidance questionnaire for sports and physical education settings (Schiano-Lomoriello et al., 2005) allowed us to verify that each set of instructions actually induced the desired goal orientation in each group, as in Study 1. Each participant was asked to complete the VSSR online by choosing foods for each of five meals from among the foods offered buffet-style (i.e., breakfast, mid-morning snack, lunch, mid-afternoon snack, and dinner).

Measures. The self-reported measure of self-regulation of eating attitudes in sports was assessed with the SREASS (Scoffier et al., 2010c), as in Study 1. The alpha coefficients were calculated as composite reliability coefficients. Both internal consistency $(\alpha>.80)$ and reliability $(\rho>$ .80) were satisfactory for each subscale of the SREASS.

The behavioral measure of self-regulation of eating attitudes in sports was measured with the VSSR (Scoffier, 2009), a virtual interface for choosing the composition of five meals a day from a wide range of food offerings. The perception of the quantity of each food chosen by the participants is based on personal eating habits using measured quantities from a container. Two sports dieticians who viewed the method as an appropriate means for assessing athletes' food habits agreed to evaluate the interface. The participants documented the duration and intensity of their physical activity on the day they completed the VSSR. The clarity of the VSSR interface was then tested on 15 students regularly participating in club sports (i.e., minimum six hours per week) $\left(M_{\text {age }}=21.00 ; S D_{\text {age }}=.28\right)$. A few adjustments in the description of quantities were made to improve the ease of use. Thus, sauces were added to enhance the flavor of foods, and their caloric value, although masked for participants, was calculated. The instructions designed to induce each goal orientation were given to the respective participants before meal construction with the VSSR in order to ensure that food choices would reflect the experimental condition. 
Two sports researchers quantitatively analyzed the data concerning energy intake. The VSSR interface assesses: (a) individual basal metabolism using the equation of Black, Coward, Cole and

3 Prentice (1996), (b) energy expenditure related to physical activity, (c) global energy expenditure, (d)

4 global energy intake, (e) the difference between energy expenditure and intake, and (f) distribution of food intake over the day. Energy intake was calculated by converting the food choices over the day into calories. Energy expenditure was determined by adding basal metabolism and the energy expenditure related to self-reported physical activity. The difference between energy intake and energy expenditure suggests the degree of self-regulation. When energy intake and expenditure are balanced, good self-regulation of eating attitudes can be assumed. With increasingly greater imbalance, increasingly less optimal self-regulation of eating attitudes should be suspected.

Analyses. The analyses performed in this second study were the same as those performed in the first study.

\section{Results}

Induction of experimental conditions. Kruskal-Wallis analysis of variance showed a significant effect of the experimental conditions $(p \leq .05)$ : the participants in each goal-orientation group ranked this goal in first position (i.e., "the goal most important to me"), thus supporting the validity of the procedure. The participants in the control group ranked MAp goals in first position.

Table 2 presents the descriptive statistics for each experimental condition. Covariance analysis performed on the post-instruction scores of self-regulation highlighted a significant effect of the covariable, the level of self-regulation of eating attitudes measured before the instructions $[(F(5,54)=$ $1.81, p<.05)]$, and also an effect of the experimental conditions $[(F(5,54)=4.28, p<.05)]$. Subsequent post-hoc Bonferroni tests revealed the following: scores of self-regulation of eating attitudes in sports were significantly higher for the control group than for the MAv group $(p<.05)$, for the control group than for the PAp group $(p<.05)$, for the PAv group than for the MAv group $(p<$ $.05)$, and for the PAv group than for the PAp group $(p<.05)$. Self-regulation of eating attitudes in sports was significantly lower for the MAv group than for the MAp group $(p<.01)$ and for the PAp group than for the MAp group $(p<.01)$.

\section{Discussion}

This study examined the influence of achievement goals on a virtual behavioral measure of the self-regulation of eating attitudes in female athletes. In agreement with our hypothesis, the athletes' capacity to self-regulate their eating attitudes, as assessed by the VSSR difference between energy intake and energy expenditure, was lower in the PAp group than in the MAp group. These results are consistent with the findings of previous correlational studies (De Bruin et al., 2009; Scoffier et al., 2009), which showed that performance goals were associated with maladaptive achievement patterns and were more likely to lead to negative eating behaviors. Furthermore, in line with the findings of Scoffier et al. (2009) and our hypothesis, the capacity to self-regulate eating attitudes was lower in the MAv group than in the MAp group. This result is consistent with the findings of previous studies that 
showed that MAv goals were associated with a fear of failure (Conroy \& Elliot, 2004), a lack of motivation (Nien \& Duda, 2008), or a decline in self-motivation (Conroy, Kaye, \& Coatsworth, 2006).

PAv goals resulted in a higher capacity to self-regulate eating attitudes than PAp goals, as suggested by Scoffier et al. (2009). As noted earlier, athletes characterized by high PAv goals might have a relatively low perception of their physical abilities. From this perspective, they would be unwilling to go to any lengths to achieve maximal performance and would thus avoid deviant behaviors like disordered eating. However, more research is needed to support this supposition.

MAp goals appeared to protect against the development of disordered eating attitudes, as they generated a higher capacity for self-regulation compared with MAv and Pap goals. Thus, as noted in the literature (Elliot \& McGregor, 2001), MAp goals were associated with adaptive achievement patterns that were generalized in the present study to eating attitudes. Interestingly, the control participants showed a natural tendency to pursue MAp goals. It is thus "normal" that the results observed for this group were comparable to those of the MAp group.

\section{General Discussion}

These two studies examined the impact of achievement goals on self-reported and behavioral self-regulation of eating attitudes. Differences were observed regarding the impact of each achievement goal. The athletes who adopted MAv goals showed less inclination to self-regulate than those who adopted MAp or PAv goals. The athletes who adopted MAp goals self-regulated more than those who adopted PAp or MAv goals. In agreement with the literature, MAv goals, which are generally associated with maladaptive feelings such as fear of failure (Elliot \& McGregor, 2001), appeared as risk factors for the development of eating disorders when compared with MAp goals, because of the low associated self-regulation. The achievement goals had a similar influence on selfreported and behavioral measures of self-regulation. These results within the $2 \times 2$ framework complete earlier studies showing that performance goals are associated with maladaptive achievement patterns with regard to eating attitudes (De Bruin et al., 2009; Scoffier et al., 2009). More generally, these findings (i.e., PAp related to a low self-regulation of eating attitudes) are consistent with studies indicating that transgressive behaviors are encouraged in situations in which winning is everything (Corrion, d'Arripe-Longueville, Chalabaev, Schiano-Lomoriello, Roussel, \& Cury, 2010). They also underline the interest of taking into account both the self-reported and behavioral aspects of selfregulation of eating attitudes.

MAp goals seemed to encourage more behavioral self-regulation than the other goal orientations, which confirms that these goal orientations are adaptive with regard to eating behaviors (De Bruin et al., 2009; Scoffier et al., 2009). In contrast, MAv goals were less likely to develop a general tendency toward self-regulation. One explanation for this difference is that the tendency to self-regulate eating behavior may be part of an ongoing obsession with food deprivation in certain athletes. Adopting MAv goals and satisfying recurrent needs to deprive oneself of food may be part of the same strategy for avoiding errors. This result confirms the literature that has at times presented 
1 MAv goals as fostering adaptive achievement patterns. For example, these goals have been positively

2 correlated with perceived competence, effort, pleasure, and physical activity (Wang, Biddle, \& Elliot,

3 2007), as well as the perception of a pleasant learning climate (Morris \& Kavussanu, 2008).

4 The effects of achievement goals in general could be further assessed by taking into account

5 perceived body image, ideal body image, and undesirable body image. Woodman and Hemming

6 (2008) showed that the bigger the gap between perceived body image and undesirable body image, the 7 more individuals will seek to attain the ideal and avoid any approach toward the undesirable image.

8 Thus, an exploration of body image might provide greater insight into how athletes psychologically

9 experience their bodies and further explain the influence of achievement goals on the self-regulation 10 of eating attitudes.

This series of studies had limitations regarding the results. First, the data for our quite sensitive variables were self-reported and may thus have been subject to social desirability bias. Second, the 13 generalizability of the results is limited because only a single and precise female population was 14 studied. Third, the participants' personal goal orientations (i.e., dispositions) were not controlled and 15 future research on eating attitudes will thus need to take into account these individual differences. In 16 addition, although we verified that the participants actually ranked the induced goal in first position, 17 other goals (PAp, PAv, MAp and MAv goals) that might have been adopted simultaneously were not 18 measured. Future studies could therefore examine the effect of an interaction of achievement goals on 19 eating attitude variables. Despite these limitations, the results of these two studies expand our 20 understanding of how achievement goals influence the self-regulation of eating attitudes in sports. 21 They can perhaps guide the motivational strategies developed by aesthetic sports coaches, and may be 22 useful for the mental preparation and health maintenance of at-risk athletes. 
References

AbuSabha, R., \& Achterberg, C. (1997). Review of self-efficacy and locus of control for nutrition and health-related behaviour. Journal of American Dietetic Association, 97, 1122-1132.

Altfas, J. R. (2002). Prevalence of attention deficit/hyperactivity disorder among adults in obesity treatment. BCM Psychiatry, 13, 2-9.

Baranowski, T., Perry, C. L., \& Parcel, G. S. (1997). How individuals, environments and health behaviour interact: social cognitive theory. In K. Glanz, F. M. Lewi, N. K. Rimer (Eds), Health Behaviour and Health Education: Theory, Research and Practice (pp. 165-181). San Francisco, CA: Jossey-Bass.

Beals, K. A., \& Manore, M. M. (2000). Behavioural, psychological and physical characteristics of female athletes with subclinical eating disorders. International Journal of Sport Nutrition \& Exercise Metabolism, 1, 128-143.

Black, A. E., Coward, W. A., Cole, T. J., \& Prentice, A. M. (1996). Human energy expenditure in affluent societies: an analysis of 575 doubly-labelled water measurements. American Journal of Clinical Nutrition, 50, 92-303.

Chi, L. (2004). Achievement goal theory. In T. Morris \& J. Summers (Eds.), Sport psychology: Theory, applications and issues ( $2^{\text {nd }}$ ed., pp.152-174). Brisbane, Aus: John Wiley \& Son.

Conroy, D. E., \& Elliot, A. J. (2004). Fear of failure and achievement goals in sport: Addressing the issue of the chicken and the egg. Anxiety, Stress, and Coping: An International Journal, 17, 271-285. doi: 10.1080/1061580042000191642.

Conroy, D. E., Kaye, M. P., \& Coatsworth, J. D. (2006). Coaching climate and the destructive effects of mastery-avoidance goals on situational motivation. Journal of Sport \& Exercise Psychology, 28, 69-92.

Corrion, K., Arripe-Longueville, F. (d'), Chalabaev, A., Schiano-Lomoriello, S., Roussel, P., \& Cury, F. (2010). Effect of implicit theories on judgment of cheating acceptability in physical education: The mediating role of achievement goals. Journal of Sport Sciences, 28, 909-919. doi: 10.1080/02640414.2010.484065.

De Bruin, K., Bakker, F. C., \& Oudejans, R. D. (2009). Achievement goal theory and disordered eating: Relationships of disordered eating with goal orientations and motivational climate in female gymnasts and dancers. Psychology of Sport \& Exercise, 10, 172-79. doi: 10.1016/j.psychsport.2008.07.002.

Desharnais, R., Bouillon, J., \& Godin, G. (1986). Self-efficacy and outcome expectations as determinants of exercise adherence. Psychological Reports, 59, 1155-1159.

Duda, J., (2001). La théorie des buts d'accomplissement et la santé dans le domaine physique [Achievement goal theory and health in physical domain]. In F. Cury \& P. Sarrazin (Eds.), 
Théories de la motivation et pratiques sportives : état des recherches [Theories of motivation in sport and physical activity contexts: Current research advances] (pp. 255-276). Paris: PUF.

Duda, J. L., \& Benardot, D. (1997). Group influences on eating and dieting behaviors in male and female varsity athletes. 2001. In H. A. Hausenblas, \& A. V. Carron (Eds.), Journal of Sport Behaviour, 23, 33-41.

Duda, J. L., \& Kim, M. (1997). Perceptions of the motivational climate, psychological characteristics, and attitudes toward eating among young female gymnasts. Journal of Sport \& Exercise Psychology, 19, S48, (NASPSPA abstracts).

Dweck, C. S. (1986). Motivational processes affecting learning. American Psychologist, 41, 10401048.

Elliot, A. J. (2005). A conceptual history of the achievement goal construct. In A. J. Elliot \& C. S. Dweck (Eds.), Handbook of competence and motivation (pp. 52-72). New York, NY: Guilford Press.

Elliot, A. J., \& Church, M. A. (1997). A hierarchical model of approach and avoidance achievement motivation. Journal of Personality and Social Psychology, 72, 218-232.

Elliot, A., \& McGregor, H. (2001). A 2 x 2 achievement goal framework. Journal of Personality and Social Psychology, 80, 501-519.

Garner, D., Olmsted, M., Bohr, Y., \& Garfinkel, P. (1982). The eating attitude test: Psychometric features and clinical correlates. Psychological Medicine, 12, 871-878.

Glynn, S. M., \& Ruderman, A. J. (1986). The development and validation of an eating self-efficacy scale. Cognitive Therapy and Research, 10, 403-420.

Herman, C. P., \& Polivy, J. (2004). The self-regulation of eating. In R. F. Baumeister \& K. D.Vohs (Eds.), The handbook of self-regulation: Research, theory, and applications (pp. 492-508). New York, NY: Guilford Press.

Hobart, J. A., \& Smucker, D. R. (2000). The female athlete triad. American Family Physician, 61, 3357-3367.

Holtkamp, K., Konrad, K., \& Müller, B. (2004). Overweight and obesity in children with AttentionDeficit/Hyeractivity Disorder. International Journal of Obesity, 28, 685-689. doi: 10.1038/sj.ijo.0802623.

Jacobi, C., Hayward, C., De Zwaan, M., Kraemer H. C., \& Agras, S. (2004). Coming to terms with risk factors for eating disorders: Application of risk terminology and suggestions for a general taxonomy. Psychological Bulletin, 130, 19-65. doi: 10.1037/0033-2909.130.1.19.

McAuley, E. (1992). Exercise and motivation: A self-efficacy perspective. In G. C. Roberts (Ed.), Motivation in sport and exercise (pp. 107-127). Champaign, IL: Human Kinetics.

McAuley, E., \& Mihalko, S. L. (1998). Measuring exercise-related self-efficacy. In J. L. Duda (Ed.), Advances in sport and exercise psychology measurement (pp. 371-390). Morgantown, WV: Fitness Information Technology. 
Morris, R. L., \& Kavussanu, M. (2008). Antecedents of approach-avoidance goals in sport. Journal of Sports Sciences, 26, 465-476. doi: 10.1080/02640410701579388.

Nicholls, J. G. (1989). The competitive ethos and democratic education. Cambridge, MA: Harvard University Press.

Nien, C., \& Duda, J. L. (2008). Antecedents and consequences of approach and avoidance achievement goals: A test of gender invariance. Psychology of Sport and Exercise, 9, 352-372. doi: 10.1016/j.psychsport.2007.05.002.

Petrie, T. A., \& Greenleaf, C. A. (2007). Eating disorders in sport: From theory to research to intervention. In G. Tenenbaum \& R. C. Eklund (Ed.), Handbook of Sport Psychology (3rd ed., pp. 352-378). Hoboken, NJ: John Wiley \& Sons.

Pinto, A. M., Guarda, A. S., Heinberg, L. J., \& DiClemente, C. C. (2006). Development of the Eating Disorder Recovery Self-Efficacy Questionnaire. International Journal of Eating Disorders, 39, 376-384. doi: 10.1002/eat.20256.

Pinto, A. M., Heinberg, L. J., Coughlin, J. W., Fava, J. L., \& Guarda, A. S. (2008). The Eating Disorder Recovery Self-Efficacy Questionnaire (EDRSQ): change with treatment and prediction of outcome. Eating Behaviours, 9, 143-153. doi: 10.1016/j.eatbeh.2007.07.001.

Pintrich, P. R. (2000). Multiple goals, multiple pathways: The role of goal orientations in learning and achievement. Journal of Educational Psychology, 92, 544-555.

Polivy, J., Herman, C. P., Mills, J. S., \& Wheeler, H. B. (2003). Eating disorders in adolescence. In G. Adams and M. Berzonsky (Eds.), Blackwell Handbook of adolescence (pp. 523-549). Oxford: Blackwell.

Rasmussen, H. N., Wrosch, C., Scheier, M. F., \& Carver, C. S. (2006). Self-regulation processes and health: The importance of optimism and goal adjustment. Journal of Personality, 74, 17211748.

Schiano-Lomoriello, S., Cury, F., \& Da Fonséca, D. (2005). Développement et validation du questionnaire d'approche et d'évitement en éducation physique et sportive (QAE-EPS). [Development and validation of the approach and avoidance questionnaire in physical education.] Revue Européenne de Psychologie Appliquée, 55, 85-98. doi: 10.1016/j.erap.2004.06.004.

Scoffier, S. (2009). Le Self Virtuel. [The Virtual Self-Service Restaurant]. Institut National de la Propriété Intellectuelle, Enveloppe Soleau, 357433. Available http://www.unice.fr/ufrstaps/ntic/self_virtuel/demo/.

Scoffier, S., Corrion, K., \& Arripe-Longueville, F. (d') (2009, September). Effect of achievement goals and social comparison on elite athletes' eating disorders. Paper presented at the International Congress of the Association for Applied Sport Psychology, Salt Lake City, UT.

Scoffier, S., Maïano, C., \& Arripe-Longueville, F. (d') (2010a). The effects of social relationships and acceptance on disturbed eating attitudes in elite adolescent female athletes: the mediating role of 
physical self-perceptions. International Journal of Eating Disorders, 43, 65-71. doi: 10.1002/eat.20597.

Scoffier, S., Paquet, Y., \& Arripe-Longueville, F. (d') (2010b). Effect of locus of control on disordered eating in athletes: The mediational role of self-regulation of eating attitudes. Eating Behaviors, 11, 164-169. doi: 10.1016/j.eatbeh.2010.01.002.

Scoffier, S., Corrion, K., Paquet, \& Arripe-Longueville, F. (d') (2010c). French development and validation of the self-regulatory eating attitude in sport scale (SREASS). Scandinivian Journal of Medicine and Sport Science, 20, 696-705. doi: 10.1111/j.1600-0838.2009.00984.x.

Sherman, R. T., \& Thompson, R. A. (2009). Body image and eating disturbance in athletes: Competing to win or to be thin? In J. J. Reels \& K. A. Beals (Eds), The Hidden Faces of Eating Disorders and Body Image (pp. 9-38). Reston, VA: AAHPERD.

Smolak, L., Murnen, S. K., \& Ruble, A. E. (2000). Female athletes and eating problems: A metaanalysis. International Journal of Eating Disorders, 27, 371-380.

Sundgot-Borgen, J. (1994). Risk and trigger factors for the development of eating disorders in female elite athletes. Medicine \& Science in Sports \& Exercise, 26, 414-419.

Sundgot-Borgen, J., \& Torstveit, M. K. (2004). Prevalence of eating disorders in elite athletes is higher than in the general population. Clinical Journal of Sport Medicine, 14, 25-32.

Van Strien, T., Frijters, J. E. R., Bergers, G. P. A., \& Defares, P. B. (1986). The Dutch Eating Behavior Questionnaire (DEBQ) for assessment of restrained, emotional, and external eating behavior. International Journal of Eating Disorders, 5, 295-315. doi:10.1002/1098-108X

Wang, C. K. J., Biddle, S. J. H., \& Elliot, A. (2007). The $2 \times 2$ achievement goal framework in a physical education context. Psychology of Sport and Exercise, 8, 147-168. doi: 10.1016/j.psychsport.2005.08.012.

Woodman, T., \& Hemming, S. (2008). Body image self-discrepancies and affect: Exploring the feared body self. Self and Social Identity, 7, 413-429. doi: 10.1080/15298860701800225. 
1

2 3

4

2 This study was financially supported by a grant from the University of Nice Sophia-Antipolis, the 3 French Ministry of Health and Sport and the France Foundation. The authors are grateful to the figure 4 skaters for their participation and the support of the French Federation of Ice Sports. They also 5 sincerely thank Catherine Carmeni for help in the English translation. 6 
Table 1

Study 1. Means (M) and Standard Deviations (SD) for Self-Regulation of Eating Attitudes in Sport Scale (SREASS) by Achievement Goal Conditions $(N=44)$

\begin{tabular}{ccc}
\hline $\begin{array}{c}\text { Experimental } \\
\text { conditions }\end{array}$ & $\mathrm{M}_{\mathrm{t} 1}$ & $\mathrm{M}_{\mathrm{t} 2}$ \\
\hline Control $(\mathrm{n}=8)$ & $4.75(.84)$ & $4.93(.01)$ \\
PAv $(\mathrm{n}=8)$ & $3.32(.32)$ & $4.93(.01)$ \\
MAv $(\mathrm{n}=10)$ & $3.15(.72)$ & $4.37(.01)$ \\
PAp $(\mathrm{n}=10)$ & $3.95(.95)$ & $4.65(.37)$ \\
MAp $(\mathrm{n}=8)$ & $3.42(.85)$ & $4.93(.01)$ \\
\hline
\end{tabular}

Notes. PAv: performance-avoidance, MAv: mastery-avoidance, PAp: performance-approach, MAp: mastery-approach. $\mathrm{t} 1$ : the measure was not performed with a specific experimental condition. $\mathrm{t} 2$ : the measure was performed after giving the instructions to induce an experimental condition. M: mean score of Self-Regulation of Eating Attitudes in Sport; standard deviation scores are presented in parentheses. 
Table 2

Study 2. Means (M) and Standard Deviations (SD) of Self-Regulation of Eating Attitudes in Sport (t1: SREASS; t2: VSSR) by Achievement Goal Conditions

\begin{tabular}{ccc}
\hline $\begin{array}{c}\text { Experimental } \\
\text { conditions }\end{array}$ & $\mathrm{M}_{\text {SREASS }}$ & $\mathrm{M}_{\mathrm{VSSR}}$ \\
\hline Control $(\mathrm{n}=10)$ & $4.38(.96)$ & $319.11(434.42)$ \\
PAv $(\mathrm{n}=10)$ & $3.55(.52)$ & $590.66(493.26)$ \\
MAv $(\mathrm{n}=12)$ & $3.15(.98)$ & $1451.72(410.65)$ \\
PAp $(\mathrm{n}=12)$ & $3.42(.62)$ & $1481.57(488.51)$ \\
MAp (n=10) & $3.63(.71)$ & $321.65(144.96)$ \\
\hline
\end{tabular}

Notes. SREASS: Self-Regulation of Eating Attitudes in Sport Scale ; VSSR: Virtual Self Service Restaurant; PAv: performance-avoidance, MAv: mastery-avoidance, PAp: performance-approach, MAp: mastery-approach. t1: the measure was not performed with a specific experimental condition. $\mathrm{t} 2$ : the measure was performed after giving the instructions to induce an experimental condition. M MREASS: mean score of Self-Regulation of Eating Attitudes in Sport Scale. M $\mathrm{VSSR}_{\mathrm{V}}$ : Mean score of Self-Regulation of Eating Attitudes in Sport Scale based on the difference between the energetic expenditure and intake; standard deviation scores are presented between parentheses. 
$\Rightarrow$ Effects of achievement goals on both self-reported and behavioral indices of selfregulation of eating attitudes in female figure skaters.

$\Rightarrow$ Induced mastery-approach goals and performance-avoidance goals resulted in higher scores for self-regulation of eating attitudes than induced performance-approach goals and mastery-avoidance goals.

$\Rightarrow$ The relationships were the same at both self-reported and behavioral levels. 


\section{Effects of Achievement Goals on Self-Regulation of Eating Attitudes in Elite Female Athletes: An Experimental Study}

\section{Point by point}

\section{Reviewers' comments:}

The numbers of page are different because we refer our number to the blind manuscript.

1. page 6 (lines 19-22) the acronym of PAP, MAV, PAV and MAP goals appears for the first time. Please do the authors modify this point?

Thanks, we added it. page 4 (lines 18-22)

2. page 10 (lines 4-5) the authors indicated that "the athletes were recruited because of their particular vulnerability to the development of disordered eating attitudes". Much more detail is needed.

We added much more detail to explain this sentence page 7 (lines 9-19).

3. page 12 (lines 17-19) add goals after MAP and not only Map.

Thanks, we added it.

4. page 17 (lines 4-7)"More generally, these findings are consistent with studies indicating that transgressive behaviors are encouraged in situations in which winning is everything." Can the authors justify this sentence in relation with the results of the study?

Thanks, we added it. page 11 (lines 25-28)

5. I also noticed a number of grammatical and typographical errors. Please have a person whose first language is English proofread your article

We apologize. We corrected any grammatical errors, and the manuscript has been reading by a person whose first language is English. 